\title{
Avain Coccidial Review
}

\author{
Batool Kadhim Meteab ${ }^{\text {a) }}$, Mahasen Abedalrazzaq ${ }^{\text {b) }}$ and Asseel Abdulridha Saeed ${ }^{\text {c) }}$
}

\author{
College of Veterinary Medicine, University of Al-Qadisiyah, Iraq
}

${ }^{a)}$ Corresponding Author: batool.alzayadi@qu.edu.iq

${ }^{b)}$ mahasen.khudeir@qu.edu.iq

${ }^{c}$ assel78.saeed@gmail.com

\section{Received : $16 / 5 / 2021$ \\ Acceptance : $12 / 4 / 2021$ \\ Available online: $31 / 12 / 2021$}

\begin{abstract}
Dep. Pathology and Poultry Diseases /coll. Vet.Med./ AL-Qadissiyah University Summary Coccdiosis consider sever disorder and necessary from an financial factor of view in poultry industry which has been controlled efficaciously for decades using more often than not anticoccidial products so the understood this disorder may additionally be help to control it. The economic impact of coccidiosis is probably underestimated, and increasing anticoccidial treatments might be useful to the broiler sector. Furthermore, a connection between subclinical coccidiosis and bacterial enteritis renders selecting the perfect tools and technique for poultry producers very difficult. Implementing sound shuttle and rotation programs is now a part of the solution for not just controlling clinical, but also subclinical coccidiosis.
\end{abstract}

Keywords. Coccidiosis, Avian, Etiology, Taxonomy, Control .

\section{INTRODUCTION}

Among the most certainly severe host specific diseases in domestic poultry farming affected all avian species and was caused by protozoa a parasites of the genus Eimeria, which thrived in the intestines of most domestic and wild animals and birds. The disorder occurs only when susceptible hosts ingest sporulated oocysts this disease characterized by diarrhea, enteritis, emaciation,drooping wings, poor growth, and increased morbidity and mortality. Poor management practices, like as wet litter and excessive stocking density, can exaggerate the scientific symptoms. [1]. The most of of Eimeria species infect birds between the ages of 3 and 18 weeks. It is associated with a significant mortality rate in chicks , In domesticated broiler, there are nine different types, four of which are edible Eimeria bruneti, Eimeria maxima, Eimeria necatrix, and Eimeria tenella are three types: Pathogens with a high severity are investigated. Mivati.E and mitis.E are the least pathogenic, whereas acervulina.E and the final two kinds are nonpathogenic. They are hagani.E and praecox.E, respectively . Chickens can infested with seven Eimeria species: E. acervulina, E. brunetti, E. maxima, E. mitis, E. necatrix, E. praecox, and E. tenella. Coccidiosis is now a challenge in the chicken industry across the world [2]. This disease consider as one of most often reported disorders across the world, and it may be seen anywhere chickens are raised [2,3]. The coccidiosis cost of was estimated to be over $\$ 2.4$ billion per year [3], on the other hand, has high costs in every country and surrounding city. The expense of coccidial management (e.g., vaccination and medication , predisposition to secondary disease, illness (e.g., Reduced overall performance as the result of decreased annual growth, feed conversion reduction and transitory decrease in egg production are key factors that influence the value of coccidiosis and its effects on the poultry production [1]. Litter wetness exceeding $30 \%$, immune deficiency, and other factors also can contribute to occurrences of medical Coccidiosis negative feeding systems, overstocking and insufficient ventilation, as well as insufficient anticoccidial inclusion environmental and management stress. Infectious (sporulated) oocysts infect susceptible hens through litter, dust, contaminated water, and feed. Infected birds deposit oocysts onto their faces, and these oocysts are a primary source of contamination for other birds [4].Direct as well as oblique touch could be used to spread the illness [5]. Infectious oocysts can also be spread mechanically by soil, equipment, insects, rodents, wild birds, and huma [6]. The disease slows the growing of affected birds and causes a high rate of morbidity and mortality [7]. The infection may be controlled with proper management, which include dry, smooth litter and adequate ventilation [8]. Anticoccidial chemicals given in the feed have been used to control coccidiosis since the 1950s, restricting infections to a subclinical level [9]. The aim of this research to present the parasite with a basic understanding and its management strategies in a manufacturing device settings, as well as parasite administration and expertise from either a poultry veterinarian and industry representative.

\section{- Etiology}

Eimeria is a species of protozoa. Because Eimeria species are rather host-specific, Perhaps a few exceptional species were infected with small cross-infected like turkeys, chicks and game birds. [10], Pathogenicity stage and infection site within the host intestinal tract were unique for each species. While each species may infect its own host, they can also attack a chicken 
at the same time. Coccidiosis is an infection caused by coccidia in a vast adequate variety and provide scientific symptoms of illness [11]. Although nine species of Eimeria have been identified as poultry coccidiosis causative agents, only seven have been demonstrated to be harmful to humans. The most pathogenic species are Eimeria tenella (E. tenella) and Eimeria necatrix (E. necatrix). Eimeria arcevulina (E. acervulina), Eimeria maxima (E. maxima), and Eimeria mivati (E. mivati) are all common and only mildly harmful, but Eimeria brunetti (E. brunetti) is rare but pathogenic in poultry. Non-pathogenic species include Eimeria mitis (E. mitis), Eimeria praecox (E. praecox), and Eimeria hagani (E. hagani) [12].

\section{- Species Identification and Taxonomy}

Coccidiosis diagnosis and genetic variation analysis in Eimeria [13], based on amplification of DNA Stucki and colleagues (1993) created a new PCR primarily based on E. tenella 5S rDNA test,and fourteen PCR diagnostic assays using arbitrary primers under low stringency. Using the internal transcribed spacer 1 regions of rDNA, tests were successful in spotting and discriminating all Chickens are infected by seven different species. These include enough interspecific diversity to allow the selection of primers for use in PCR investigations to distinguish species [14,15]. Gruber and colleagues had developed an alternative approach involves converting anonymously polymorphic DNA markers amplified in random into sequence-characterized amplified location markers [16]. There seem to be a number of molecular (PCR-based) and computational (COCCIMORPH) approaches that can be used to identify species.

Peculiarity [17], Early study on Eimeria taxonomy and their relations to Small businesses was entirely focused on morphological and biological characteristics [18]. The evolutionary relationships of Eimeria species infecting the bird have been determined according to Barta and colleagues' analysis of specific subunit (18S) rDNA gene sequences [19]. The According to a most probable consensus tree created from numerous Eimeria species the eimeriid coccidia clade is not monophyletic, suggesting that This genus' taxonomy is far from complet determined [20]. To the absence of the various species that infect poultry, coccidia from the cecum of hens and turkeys (i.e., Eimeria necatrix, Eimeria tenella, and Eimeria adenoeides) were discovered to be monophyletic [21].
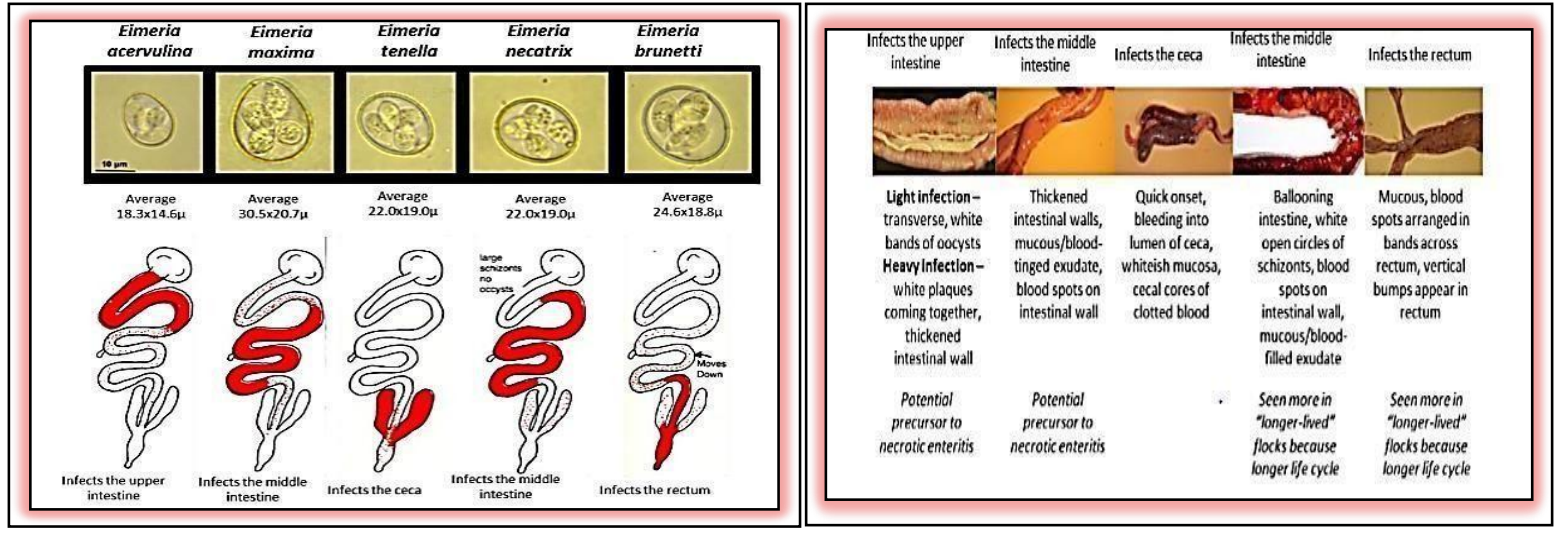

FIGURE 1. Shown common fowl Eimeria species associated with disease. Eimeria oocysts and location of infection along the intestine and lesions per species [22].
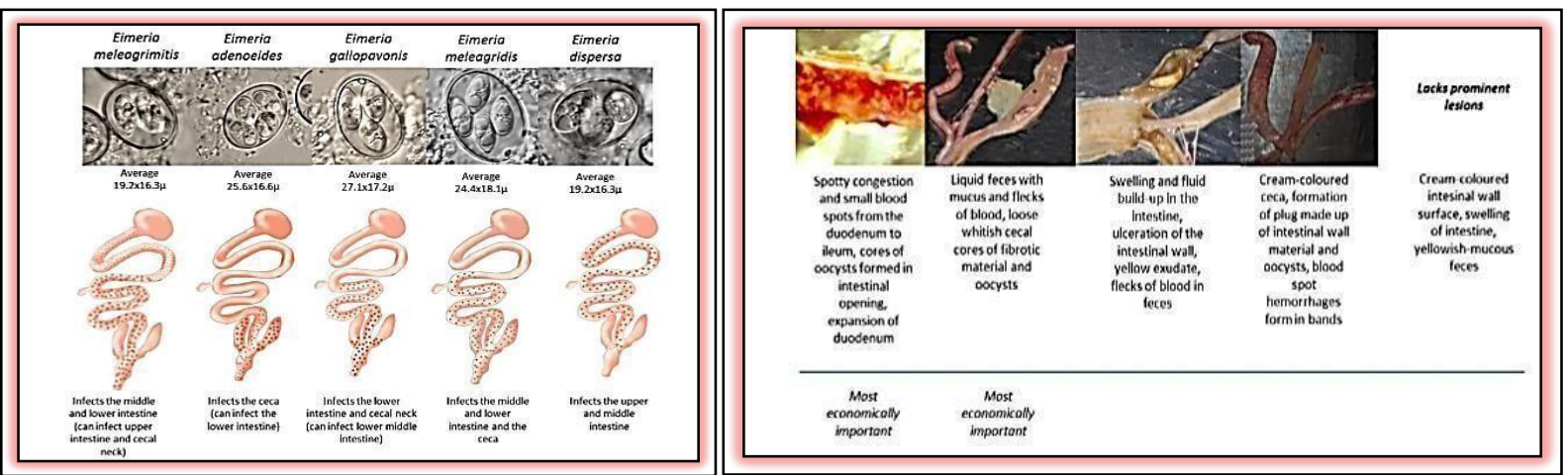

FIGURE 2. Shown the Five species of turkey Eimeria commonly related to infection. Eimeria oocysts and location of infection along the intestine and lesions per species [23-25]. 
The direct, Short life cycle, sexual and asexual phases with strong reproductive workability make a single oocyst can create 1,500,000 oocysts. The fecal-orally transmitted environmentally resistant oocyst is made up of four sporocysts, each with two infective sporozoites. Sporozoites will leave the sporocyst and infect a host intestinal epithelial cell, where they will reproduce asexually for the rest of their lives. a number of cycles that must be completed in a certain amount of time poultry sexual reproduction results in an uninfected oocyst [26]. Sporulation can takes place in the backyard of the host when the oocyst is in the right temperature, oxygen stage, and relative humidity itcan become infective [27], in most Eimeria species, the sporulation takes about 48 hours [26]. Most will shed 6 to 8 days after inoculation during the patent period, this will taper out about 10 days following inoculation [28]. The amount of Eimeria oocysts ingested impacts the severity of the host's damage [29]. Depending on the Eimeria species, "a few" oocysts can cause in an undetectable infection, "thousands" can cause in clinical symptoms, and "tens of thousands" can cause in clinical signs. The end result is coccidiosis. and possibly rise in mortality rate in birds that have never been exposed to the disease [29].

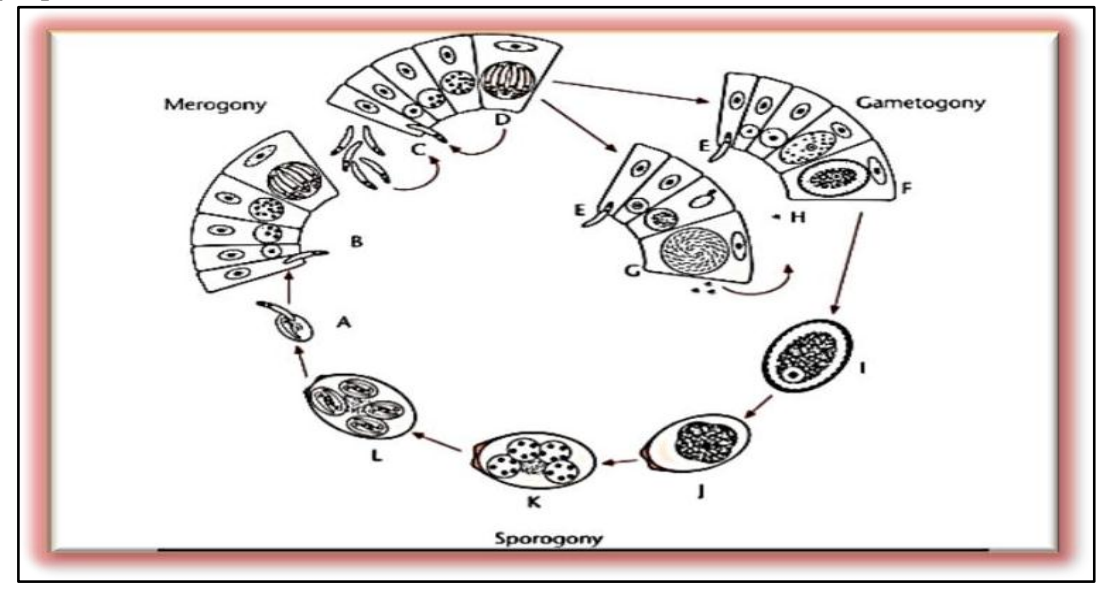

FIGURE 3. Cycle Life of of Eimeria.

\section{- Invasion of the Host Cell}

Invasion is a dynamic process that begins with the creation in a transferring at the parasite/host cell membrane interface, which makes its way to parasite's the back end [30]. Tomley and colleagues provided a specific proteomic evaluation of one of a kind life cycle stages of E. tenella, and There were 1,868 proteins found, including the the transferring factor. The invasion cells of the host have both process merozoites and sporozoites. In the 1990s, subcellular fractionation technologies made it possible to isolated organelles from sporozoites, including micronemes, rhoptries, and dense granules, as well as describe numerous proteins produced as a result of parasite invasion of host cells [31], one of which is Micron's protein. In E. tenella, epidermal growth factor-like repeats and thrombospondin type-1 repeats in tandem arrays were identified in EtMIC4. [32], $\mathrm{RON}_{2}, \mathrm{RON}_{4}, \mathrm{RON}_{5}, \mathrm{AMA}-1$, and AMA-2 these are junction proteins and involved in host cellphone invasion [33]. $\mathrm{RON}_{2}$ was detected in both sporozoites and merozoites, however AMA-1 and RON4 were only found in merozoites and AMA-2 and RON5 were only found in sporozoites, implying that transferring junction proteins are stage-specific. After sporulation, the microneme and most rhoptry proteins were completely identified. A gene encoding an immune dominant protein produced by micronemes from E. tenella sporozoites was sequenced, and it was discovered to be. Cell-to-cell or cell-to- interactions between matrices This project has resulted in structural and valuable data based on feature of proteins produced by micronemes in the host cellphone and focus point in fantastic atomic issue as a result of continuing this work [34].

\section{- Pathology}

Eimeria species in chicken advance in unique locations of the gut, where they can cause moderate to severe lesions and significant pathology, depending on the degree of infection that Tyzzer and colleagues confirmed it . Thus, $E$. acervulina and E. praecox can advance in the duodenum, with heavy infections spreading to the mid-intestine, while E. maxima, E. mitis, and E. necatrix strengthen poultry in the mid-intestine, with heavy infections reaching to the intestines of the back posterior intestine, while E. tenella develops in the ceca [35]. E. brunetti was discovered by accident [36]. A seventh species has been added, which grows in the rectum and lower intestine Depending on the type of illness, its severity, and its location, (E. brunetti and E. maxima), coccidiosis can cause a limited enteritis with fluid loss and mal absorption of vitamins, as well as inflammation of the intestinal wall with pinpoint hemorrhages and epithelia sloughing, or the complete destruction of the villar, culminating in a mortality due to a big hemorrhage (E. 
necatrix andE.tenella).Eimeria praecox was believed to be low pathogenicity with low or little damage. These and other characteristics have been included into the commonly used visual machine for assessing the severity of lesions in various parts of the stomach [37]. Several studies have been conducted. looked into the consequences of specific Dietary ingredients on coccidiosis, including as 1-arginine, threonine, a variety of vitamins, as well as so-called plant-based foods herbal goods [38-40]. Coccidiosis affects glucose, oleic acid, food A, carotenoids, calcium, and trace minerals including zinc absorption in the duodenum of birds infected with E. acervulina has been explored, and in the majority of cases, poor absorption has been discovered [41]. Various species of Eimeria have been the subject for a few studies [42] Glucose and Amino acid absorption was difficult because poor Increased uptake in the ileum could compensate for absorption in the duodenum. [43]. Infection can cause changes in mucosal permeability, resulting in plasma protein leakage into the intestinal lumen, increased $\mathrm{pH}$, and decreased gut motility [44-46]. Infection with E. maxima causes severe hypoproteinemia, a drop in thyroxine and triiodothyronine plasma concentrations, with a rise in plasma corticosterone and testosterone an increase in corticosterone and prolactin levels in the blood [47,48]. No alterations in growth hormone were discovered, showing that this hormone is no longer implicated amid a period of slowing growth seen when an infection is present.

\section{- Eimeria and Necrotic Enteritis Interaction}

Coccidiosis with necrotizing enteritis Infections are usually inseparable. This bacterial disease caused by Clostridium perfringens, which primarily affects the small intestine [49]. [50], Necrotic enteritis also can caused by a compromised gut wall induced by predisposing factors such as meal plan content and intestinal line damage. Coccidiosis seems to be a parasitic infection that causes coccidiosis [51]. Cl. perfringens is deficient in approximately 13 critical amino acids that the host can give [50]. It can get these amino acids from their hosts in a number of ways, including protein leaks. And made comprised of a variety of amino acids) enters the intestine after an intestinal cell damage or through the mucous (The lining of the digestive tract which is largely glycoproteins and water)[51].As a result, Eimeria species that destroy E. maxima, E. acervulina, , E. brunetti, or E. necatrix attacked small intestinal cells and induce an increase in mucous production during infection, can predispose birds to necrotic enteritis later on [51]. Other Eimeria species (E. praecox and E. mitis) cause increased mucous production in the small intestine. The intestine is inflating and thin, brittle, frequently translucent intestinal walls, Hyperemia of the mesenteric intestinal blood vessels are among the symptoms of necropsy. At the end of the gastro-intestinal tract (GIT), frothy contents or watery, poorly digested feed particles multi-colored oily substance of the gut contents in touch with the mucosa The following are some often encountered sign:

Feed consumption is stalling ,Feed particles that are greasy and poorly digested are prevalent., while water consumption is increasing every day in accordance with breed norms, resulting in a high water: feed ratio (WFR). In normal ambient conditions, the WFR during a normal episode of bacterial enteritis exceeds. Additionally, water consumption is halting in a later phase, feathers that are filthy as a result of moist litter and reduced feeding and drinking activity.

\section{- Prevention and Control Biosecurity}

Most disinfectants employed in the fight against other diseases are unable to penetrate the wall of oocysts and destroy the sporozoites that are infective. When a wpoultry oocyst is kept at $4{ }^{\circ} \mathrm{C}$ in the lab, it can live for up to 2 years. Infectious oocysts have also been shown to survive in soil for up to 602 days [52]. Despite the fact that, The wall of the oocyst is not sticky. It's possible moved by way of People, rats, flies, dust, and even compressed air movements are all sources of contamination. Furthermore, oocysts can linger in porous or crevices surfaces (e.g. cement) in the barn environment, thus the cleaner must take particular precautions with these areas when cleaning the barn.

\section{- Vaccination}

In live non-attenuated immunization, the restricted parasite copy of a single organism is combined with the host's innate capacity to minimize clinical signs and symptoms of Eimeria infection.In other words, live vaccinations activate the host's immune response while limiting parasite reproduction and oocyst output with no medical or subclinical harmful effects.. The first exposure is provided by the oocysts in the vaccine, and the second is produced by cycled oocysts transferred by fecal-oral transmission. The variety of oocysts in the preliminary vaccination dose determines the range of oocysts cycled. When a chicken develops protective immunity against a certain Eimeria species, it is no longer vulnerable to infection. [53], With all live coccidiosis vaccines, there is a first-class consistency between delivering enough parasites with bicycling to reduce scientific signs and symptoms vs having so many biking parasites that intestinal lesions arise. Antibiotics are drugs that are used to treat bacterial infections.

For prevention coccidial infections Anticoccidial pills are antibiotics added to the feed in order to avoid used, these medications are given in modest doses beginning on the first life. They can also be dissolved in water to treat or prevent 
illnesses. Wallenstein Feed \& Supply's Janet Schell reported that Several anticoccidial capsules can have a coccidiostatic effect when Eimeria development in the colon and eventually may kill it. Anticoccidial capsules are or have been utilized in the poultry sector, including but not limited to [54-57]. Ionophore is a coccidiocide and coccidiostat which produced by fermentation (of a range of bacteria, like Streptomyces and Actinomadura species) and they works by breaking the parasite membrane. two Chemicals - synthetic molecules made possible by chemical potential.

In 1978, Lilly Research Laboratories leased a commercial broiler production plant in Alabama and then Arkansas to explore monensin-nutrition interactions in a controlled environment (R. H. Wellenreiter, Lilly Research Laboratories, unpublished data). [58] Monensin is not as effective in chickens fed a wheat-based diet as it is in chicks fed a maizebased diet it was previously thought to have no effect on sodium or TSAA levels. broiler's requirements but it has been shown in numerous studies to inhibit growth in chicks [57], which is aggravated by low-protein diets[59]. [60], This was originally attributed to E. tenella's lower pathogenicity in maize- fed birds, which was thought to be related to the protective effects of higher vitamin A and E concentrations and lower niacin and riboflavin ranges in maize compared towheat.

\section{CONCLUSION}

Several of the major accomplishments in the study of avian coccidiosis discussed in this article. Because chicken production is subject to constant change, coccidiosis-related issues also alter over time. Although recent advances in molecular techniques have raised expectations, practical applications of these techniques are now uncommon. In order to detect coccidiosis, the industry must rely on connected approaches, which, if utilized correctly, can still result in a significant expense. Because bacterial enteritis is now one of the most serious issues affecting the poultry industry's performance, the function of coccidiosis in this multifactorial condition must be properly evaluated. Anticoccidials may be able to achieve desirable results by diminishing BE's impact. Whether these findings are attributable to direct antibacterial actions or indirect effects on coccidia need to be determined. Understanding the parasite and how to handle it in a production device can help with parasite management. Anticoccidials may want to have a really helpful outcomes with the aid of reducing the impact of BE, however if these outcomes are due to direct antibacterial, or indirect by means of the consequences on coccidia, stays to be similarly investigated. Understanding the parasite and how to handle it in a production device can help with parasite management. Anticoccidials may have beneficial outcomes by lowering the influence of BE; however, whether these outcomes are due to direct antibacterial action or indirect action through coccidia effects yet to be determined. Eimeria's Although Eimeria's research has been lagging behind other apicomplexan parasites. modern molecular biology as well as telephone technologies in biology have already been employed to considerably increase our understanding of these organisms in recent years.

The toughness of the oocyst, as well as its widespread prevalence wherever roosters are kept, poses a constant threat to chicken health. and consequently There will be some a persevered basic requirements and utilized lookup into all elements. a study of these species' biology The latest completing the genomic sequences of every infecting species poultry maintains superb the promise of accelerated control in the future. As a result, there will be an ongoing demand for scientific and applied research into all aspects of these species' biology. The most recent completion of the genomic sequences first and foremost organisms that infect poultry offers out excellent hope for better control in the future .

\section{REFERENCES}

[1] Price, K.R., M.T. Guerin, L. Newman, B.M. Hargis, and J.R. Barta. 2013 Examination of a novel practical poultry management method to enhance the effect of live Eimeria vaccination for conventionally housed replacement layer pullets. International Journal of Poultry Science 12:175- 184. 2013

[2] Zhang, J.J., L.X. Wang, W.K. Ruan, and J. An. 2013 Investigation into the prevalence of coccidiosis and maduramycin drug resistance in chickens in China. Veterinary Parasitology 191:29-34. 2013.

[3] Price, K.R. 2012 Use of live vaccines for coccidiosis control in replacement layer pullets. Journal of Applied Poultry Research 21:679-692.2012.

[4] Al-Taee A. F and Al- Neema M. S. S. The pathological changes accompanied with the infection of Eimeria in intestine of broiler in Al-Hamdania Region Anbar Journal of Veterinary Sciences, Volume 5, Issue 2, 2012 6527-1999.

[5] Mc Dougald L R. Coccidiosis. In: Diseases of Poultry. 11th edition. Saif Y M, Barnes H J, Glisson J R, Fadly A M, McDougald R L and Swayne D E, (Eds) loa State Press, Blackwell publishing Company, USA., pp: 974-991, 2003.

[6] Williams R B . Anticoccidial vaccines for broiler: pathways to success. Avian Pathology, 31: 317-353, 2002.

[7] Dimitrijevic S and Ilic T . Kokcidioza zivine, monografija, Fakultet veterinarske medicine, Univerzitet u Beogradu, 2003.

[8] Anjum A D. Prevalence of Poultry diseases in and around Faisalabad and their relationship to weather. Pakistan Veterinary Journal, 10: 42-45, 1990.

[9] Jordan F T . Poultry diseases. Third edition, the cambridge university press, 1995.

[10] Danforth H D . Use of live oocyst vaccines in the control of avian coccidiosis: experimental studies and field trials. 
[11] Fayer, R. Epidemiology of protozoan infections: the coccidia. Veterinary Parasitology 6:75- 103. 1980.

[12] Conway D, Mckenzie M (2007) Poultry Coccidiosis, Diagnostic and Testing Procedures. (3rd edn), Ames, Iowa. Blackwell publishing, USA, p. 37-40.10.

[13] Lillehoj H, Trout J (1993) Coccidia: A Review of Recent Advances on Immunity and Vaccine Development Avian pathology 22: 3 - 31. Poultry Research 21:679-692.2012.

[14] Morris,G.M. and Gasser,R.B.(2006) Biootechnologycal advances in the diagnosis of avian coccidiosis and the analysis of genetic variation in Eimeria. Biotechnology advance 24: 590-603

[15] MacPherson, J. M., and A. A. Gajadhar. 1993. Differentiation of seven Eimeria species by random amplified polymorphic DNA. Vet. Parasitol. 45:257-266.

[16] Schnitzler, B. E., P. L. Thebo, J. G. Mattsson, F. M. Tomley, and M. W. Shirley. 1998. Development of a diagnostic PCR assay for the detection and discrimination of four pathogenic Eimeria species of the chicken. Avian Pathol. 27:490-497.

[17] Fernandez, S., A. C. Costa, A. M. Katsuyama, A. Madeira, and A. Gruber. 2003. A survey of the inter- and intraspecific RAPD markers of Eimeria spp. of the domestic fowl and the development of reliable diagnostic tools. Parasitol. Res. 89:437-445

[18] Castañón, C. A. B., J. S. Fraga, S. Fernandez, A. Gruber, and L. F. Costa. 2007. Biological shape characterization for automatic image recognition and diagnosis of protozoan parasites of the genus Eimeria. Pattern Recognit. 40:1899-1910.

[19] Levine, N. D., J. O. Corliss, F. E. G. Cox, G. Deroux, J. Grain, B. M. Honigberg, G. F. Leedale, R. Loeblich, J. Lom, D. Lynn, E. G. Merinfeld, F. C. Page, G. Poljansky, V. Sprague, J. Vavra, and F. G. Wallace. 1980. A newly revised classification of the protozoa. J. Protozool. 27:37-58.

[20] Barta, J. R., D. S. Martin, P. A. Liberator, M. Dashkevicz, J. W. Anderson, S. D. Feighner, A. Elbrecht, A. PerkinsBarrow, M. C. Jenkins, H. D. Danforth, M. D. Ruff, and H. Profous-Juchelka. 1997. Phylogenetic relationships among eight Eimeria species infecting domestic fowl inferred using complete small subunit ribosomal DNA sequences. J. Parasitol. 83:262-271.

[21] Chapman, H. D., J. R. Barta, D. P. Blake, A. Gruber, M. Jenkins, N. C. Smith, X. Suo, and F. M. Tomley. 2013. A selective review of advances in coccidiosis research. Adv. Parasitol. 83:93 - 171.

[22] Miska, K. B., R. S. Schwarz, M. C. Jenkins, T. Rathinam, and H. D. Chapman. 2010. Molecular characterization and phylogenetic analysis of Eimeria from turkeys and gamebirds: Implications for evolutionary relationships in galliform birds. J. Parasitol. 96:982-986.

[23] Reid, W.M., and P.L. Long. A diagnostic chart for nine species of fowl coccidia. College of Agriculture Experiment Stations, University of Geogia. 1979 .

[24] Thank you to Dr. Jean-Michel Reperant for chicken Eimeria oocyst photos and E. meleagrimitis lesion photo.

[25] Reid, M.W., P.L. Long, and L.R. McDougald. Coccidiosis. In: Diseases of Poultry, 8 ed. M.S. Hofstad, B.W. Calnek, M.W. Reid and H.W. Yoder Jr., eds. Iowa State University Press, Ames, Iowa, USA. pp 692717. 1984.

[26] Shiem El-Sherry for the turkey Eimeria oocyst photos and E. adenoeides, E. gallopavonis and E. meleagridis photos Barta, J.R. Coccidiosis. In: eLS. 2001.

[27] Fayer, R. Epidemiology of protozoan infections: the coccidia. Veterinary Parasitology 6:75- 103. 1980.

[28] Kheysin, Y.M. Life Cycles of Coccidia of Domestic Animals. University Park Press, Baltimore, MD. 1972.

[29] Price, K.R. Use of live vaccines for coccidiosis control in replacement layer pullets. Journal of Applied Poultry Research 21:679-692.2012.

[30] Tomley, F. M., L. E. Clarke, U. Kawazoe, R. Dijkema, and J. J. Kok. 1991. Sequence of the gene encoding an immunodominant microneme protein of Eimeria tenella. Mol. Biochem. Parasitol. 49:277-288.

[31] Tomley, F. M., K. J. Billington, J. M. Bumstead, J. D. Clark, and P. Monaghan. 2001. EtMIC4: A microneme protein from Eimeria tenella that contains tandem arrays of epidermal growth factorlike repeats and thrombospondin type-1 repeats. Int. J. Parasitol. 31:1303-1310.

[32] Russell, D. G. 1983. Host cell invasion by Apicomplexa: An expression of the parasite's contractile system? Parasitology 87:199-209.

[33] Lal, K., E. Bromley, R. Oakes, J. H. Prieto, S. J. Sanderson, D. Kurian, L. Hunt, J. R. Yates,

[34] J. M. Wastling, R. E. Sinden, and F. M. Tomley. 2009. Proteomic comparison of four Eimeria tenella life-cycle stages: Unsporulated oocyst, sporulated oocyst, sporozoite and second- generation merozoite. Proteomics 9:4566-4576.

[35] Cowper, B., S. Matthews, and F. M. Tomley. 2012. The molecular basis for the distinct host and tissue tropisms of coccidian parasites. Mol. Biochem. Parasitol. 186:1-10.

[36] Joyner, L. P. 1978. The identification and diagnosis of avian coccidiosis. Pages 29-49 in Avian Coccidiosis. Proc. 13th Poult. Sci. Symposium. P. L. Long, K. N. Boorman, and B. M. Freeman, ed. British Poultry Science Ltd., Edinburgh, UK.

[37] Levine, P. P. 1942. A new coccidium pathogenic for chickens, Eimeria brunetti n. species (Protozoa: Eimeriidae). Cornell Vet. 32:430-439.

[38] Johnson, J., and W. M. Reid. 1970. Anticoccidial drugs: Lesion scoring techniques in battery and floor-pen experiments with chickens. Exp. Parasitol. 28:30-36

[39] Allen, P. C., H. D. Danforth, and P. C. Augustine. 1998. Dietary modulation of avian coccidiosis. Int. J. Parasitol. 28:1131-1140.

[40] Allen, P. C., and R. H. Fetterer. 2002. Effects of dietary vitamin E on chickens infected with Eimeria maxima: Observations over time of primary infection. Avian Dis. 46:839-846.

[41] Wils-Plotz, E. L., M. C. Jenkins, and R. N. Dilger. 2013. Modulation of the intestinal environment, innate immune response, and barrier function by dietary threonine and purified fiber during a coccidiosis challenge in broiler chicks. 
[42] Turk, D. E., and J. F. Stephens. 1967. Upper intestinal tract infection produced by E. acervulina and absorption of $65 \mathrm{Zn}$ and 131Ilabelled oleic acid. J. Nutr. 93:161-165.

[43] Turk, D. E. 1978. The effects of coccidiosis on intestinal function and gut microflora. Pages 227-267 in Avian Coccidiosis. Proc. 13th Poultry Science Symposium. P. L. Long, K. N. Boorman, and B. M. Freeman, ed. British Poultry Science Ltd., Edinburgh, UK.

[44] Ruff, M. D. 1974. Reduced transport of methionine in intestines of chickens infected with Eimeria necatrix. J. Parasitol. 60:838-843.

[45] Schildt, C. W., and C. A. Herrick. 1955. The effect of cecal coccidiosis on the motility of the digestive tract of the domestic fowl. J. Parasitol. 41:18-23.

[46] Stephens, J. F. 1965. Some physiological effects of coccidiosis caused by Eimeria necatrix in the chicken. J. Parasitol. 51:331-335.

[47] Preston-Mafham, R. A., and A. H. Sykes. 1967. Changes in the permeability of the mucosa during intestinal coccidiosis infections in the fowl. Experientia 23:972-973.

[48] Chapman, H. D., D. L. Fernandes, and T. F. Davison. 1982. A comparison of the effects of infection with Eimeria maxima and dietary restriction on weight gain, plasma metabolites and liver glycogen in the immature fowl, Gallus domesticus. Parasitology 84:205-213.

[49] Davison, T. F., H. D. Chapman, and S. Harvey. 1985. Endocrine changes in the fowl during infection with Eimeria maxima. Res. Vet. Sci. 38:296-300.

[50] Timbermont, L., F. Haesebrouck, R. Ducatelle, and F. Van Immerseel. Necrotic enteritis in broilers: an updated review on the pathogenesis. Avian Pathology 40:341-347. 2011.

[51] Cooper, K.K., and J.G. Songer. Necrotic enteritis in chickens: a paradigm of enteric infection by Clostridium perfringens type A. Anaerobe 15:55-60. 2009.

[52] Williams, R.B. Intercurrent coccidiosis and necrotic enteritis of chickens: rational, integrated disease management by maintenance of gut integrity. Avian Pathology 34:159-180. 2005.

[53] Reid, M.W. History of avian medicine in the United States. X. Control of coccidiosis. Avian Diseases 34:509-525. 1990.

[54] Chapman, H.D. Practical use of vaccines for the control of coccidiosis in the chicken. World's Poultry Science Journal 56:7-20.2000.

[55] Chapman, H.D. Anticoccidial drugs and their effects upon the development of immunity to Eimeria infections in poultry. Avian pathology 28:521-535. 1999.

[56] Chapman, H.D., T.K. Jeffers, and R.B. Williams. Forty years of monensin for the control of coccidiosis in poultry. Poultry Science 89:1788-1801.2010.

[57] Keshavarz, K., and L. R. McDougald. 1982. Anticoccidial drugs: Growth and performance depressing effects in young chickens. Poult. Sci. 61:699-705

[58] Parsons, C. M., and D. H. Baker. 1982. Effect of dietary protein level and monensin on performance of chicks. Poult. Sci. 61:2083-2088.

[59] Welch, C. C., C. M. Parsons, and D. H. Baker. 1988. Further investigation of the dietary protein level-monensin interrelationship in broiler chicks: Influence of dietary protein source and type of anticoccidial drug. Poult. Sci. 67:652659.

[60] Williams, R. B. 1992. Differences between the anticoccidial potencies of monensin in maize- based or wheat-based chicken diets. Vet. Res. Commun 16:147-152. 